\title{
Primary Sampling Unit
}

National Cancer Institute

\section{Source}

National Cancer Institute. Primary Sampling Unit. NCI Thesaurus. Code C67108.

A designated geographic area consisting of either metropolitan areas containing a

central city of 50,000 or larger population, or counties or groups of counties containing small cities and rural areas. 